
Not for reproduction, distribution or commercial use.

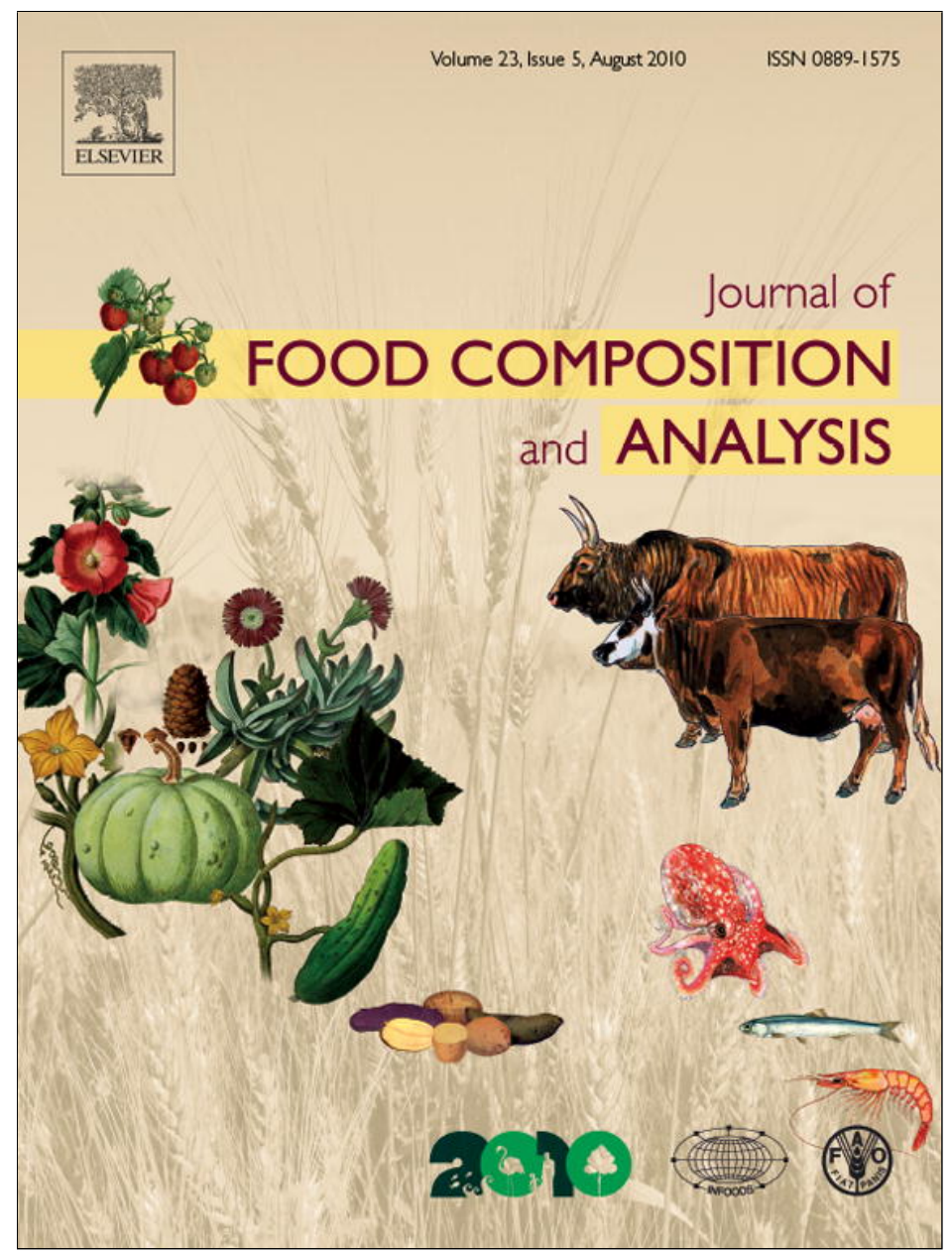

This article appeared in a journal published by Elsevier. The attached copy is furnished to the author for internal non-commercial research and education use, including for instruction at the authors institution and sharing with colleagues.

Other uses, including reproduction and distribution, or selling or licensing copies, or posting to personal, institutional or third party websites are prohibited.

In most cases authors are permitted to post their version of the article (e.g. in Word or Tex form) to their personal website or institutional repository. Authors requiring further information regarding Elsevier's archiving and manuscript policies are encouraged to visit:

http://www.elsevier.com/copyright 
Original Article

\title{
Influence of oenological practices on the formation of biogenic amines in quality red wines
}

\author{
Matilde García-Marino, Álvaro Trigueros, Teresa Escribano-Bailón * \\ Grupo de Investigación en Polifenoles, Unidad de Nutrición y Bromatología, Facultad de Farmacia, Universidad de Salamanca, Campus Miguel de Unamuno, 37007 Salamanca, Spain
}

\section{A R T I C L E I N F O}

\section{Article history:}

Received 13 January 2009

Received in revised form 29 January 2010

Accepted 18 February 2010

\section{Keywords:}

Red wine

Biogenic amines

Histamine

Organic wine

Yeast mannoproteins

Food composition

Food analysis

\begin{abstract}
A B S T R A C T
Changes in the contents of biogenic amines (histamine, putrescine, tyramine, cadaverine, agmatine, ethylamine, isobutylamine, phenyletilamine, isoamylamine, serotonine and tryptamine) were studied during the winemaking process of quality red wines, including an organic wine. The analytical method used was validated in terms of linearity, precision, coefficient of variation and recovery. The limits of detection and quantification of the amines were also calculated. The method involved pre-column automated derivatisation of the amines by treatment with o-phthalaldehyde, after which the derivatives formed were analysed by reverse-phase HPLC. Results showed that grape must already contains biogenic amines and this content tends to increase throughout winemaking and maturation. The organic wine showed higher levels of biogenic amines than the non-organic wine. The fact that malolactic fermentation occurs spontaneously in organic wines, together with low levels of $\mathrm{SO}_{2}$ because of legal restrictions, could be responsible for the higher levels in biogenic amines found. For the non-organic wine, 2 oenological practices could increase the content in biogenic amines: the addition of press wine to the free run wine, and the treatment with yeast mannoproteins.
\end{abstract}

(๖) 2010 Elsevier Inc. All rights reserved.

\section{Introduction}

Biogenic amines (BAs) are organic bases of low molecular weight, which play an important role as endogenous regulators of diverse physiological processes in the human organism. Moreover, they can be present in foodstuffs in variable proportions as a result, generally, of the existence of fermentative processes or because of bacterial contamination. When foodstuffs containing biogenic amines are ingested, adverse effects, whose gravity depends on the quantity ingested, can be produced in the organism. The symptoms associated with the ingestion of BAs range from headaches, shortness of breath and tachycardia if small doses have been ingested, to vomiting, bronchial constriction, hyper and hypotension, kidney and vascular failure, etc. when the quantity ingested has been higher (Silla-Santos, 1996; Taylor, 1986; Rivas-Gonzalo et al., 1983).

Among the BAs, histamine is the most toxic and thus the most commonly sought after, although its effects can be potentiated by the presence of other amines, such as spermine, spermidine, putrescine or agmatine (Bauza et al., 1995; Chu and Bjeldanes, 1981). The sensitivity of individuals to the BAs varies in accordance with the individual capacity for detoxification (Bauza et al., 1995; Jung and Bjeldanes, 1979; Taylor and Lieber, 1979; Maynard and

\footnotetext{
* Corresponding author. Tel.: +34 9232945 37; fax: +34 923294515

E-mail address: escriban@usal.es (T. Escribano-Bailón).
}

Schenker, 1962). Therefore, when the toxic effects of the BAs are considered, as well as the total concentration of amines, the ingestion together with ethanol and/or determined medicines must be taken into account. In fact, whereas in products such as meat and fish derivatives the adverse effects of certain amines (phenylethylamine, for example) appear after the ingestion of $53 \mathrm{mg}$, in wines doses of $3 \mathrm{mg}$ can be enough (Glória et al., 1998; Bauza et al., 1995; Sandler and Reynolds, 1976; Rivas-Gonzalo et al., 1983). The complexity of the interactions of the amines that take place among them and with other substances is the principal factor responsible for the difficulty in establishing maximum limits for these compounds in foodstuffs.

The BAs can be produced by the decarboxylation of determined amino acids (for example, histamine originates by the decarboxylation of histidine) by enzymes produced by some lactic bacteria (LB) responsible for fermentative processes undergone by foodstuffs such as cheeses, cold meats, pickles and wines (Bauza et al., 1995; Buteau et al., 1984; Vidal-Carou et al., 1990; Lonvaud-Funel, 2001).

The evolution and presence, both qualitative and quantitative, of BAs in wines is still not well defined and, at times, there is a lack of agreement between the published results (Gerbaux and Monamy, 2000; Coton et al., 1998; Soufleros et al., 1998; Pogorzelski, 1992; Ough et al., 1987). At present, the tendency is to accept the existence of malolactic fermentation (MLF) as one of the most important factors that determine their presence. 
The fact that the majority of white wines do not undergo MLF, together with the fact that, consequently, their $\mathrm{pH}$ is generally lower than that of red wines, results, frequently, in the content of BAs of white wines being smaller than that of red wines, which is between 0 and $130 \mathrm{mg} / \mathrm{L}$ (Gerbaux and Monamy, 2000; Soufleros et al., 1998; Cilliers and Van Wyk, 1985; Zee et al., 1983; Glória et al., 1998). Nonetheless, it does not appear to be the only factor to take into account. Among the LBs, not all of them have the enzymatic equipment necessary to decarboxylate the amino acids and, consequently, give rise to the formation of BAs (Moreno-Arribas et al., 2003; Coton et al., 1998). One of the factors that determine not only the biological activity of the bacteria in wine, but also its variety is the $\mathrm{pH}$. With the objective of attending to the demands of the consumer, wines tend to be less acid than in the past. The ripening of the grape tends to be prolonged to the maximum possible with the aim of increasing the extractability of the phenolic compounds and the concentration of the aroma precursors. As a result the acidity of wines tends to be lower and the $\mathrm{pH}$ higher. Consequently, the number and type of bacterial microflora found present during winemaking increases and with it the possibilities of formation of BAs (Lonvaud-Funel and Joyeux, 1994).

Although the microbiology of the MLF in wines, at present, tends to be more controlled through the use of selected starters, in many cellars it continues to develop spontaneously from autochthonous bacteria, since they are better adapted to conduce the MLF of their wines than other commercial generics from strains that have not been isolated in the zone of production of the cellar.

Another factor to be borne in mind is the possible formation of BAs during the maturation and ageing of the wine. Indeed, in recent studies, a progressive increase in the content of certain amines has been demonstrated during ageing, particularly of histamine, tyramine, putrescine and diaminobutane (Herbert et al., 2004; Jiménez-Moreno et al., 2003; Gerbaux and Monamy, 2000). After the MLF the wine is sulphited with the objective of eliminating the yeasts and residual bacteria, but due to the rise in $\mathrm{pH}$ and also to the fact that it is found in part combined with the polyphenols, the activity of the $\mathrm{SO}_{2}$ decreases and this can give rise to some lactic bacteria remaining viable months after the winemaking and conserving certain biological activity, fundamentally that which helps their survival.

Thus, the decarboxylation of the amino acids is a mechanism that allows the bacteria to obtain energy when other sources have already been metabolised (Lonvaud-Funel, 1999; Rollán et al., 1995), so the strains that present this activity can survive longer than those which do not.

Furthermore, such amines as putrescine, spermidine, methylamine, ethylamine, phenylethylamine, isoamylamine and cadaverine, among others, can already be found in the grapes and must (Lonvaud-Funel, 2001; Vidal-Carou et al., 1990; Buteau et al., 1984; Ough and Daudt, 1981) as well as being produced (and also degraded) during the winemaking. It has been demonstrated that many strains of yeasts present in wines (Saccharomyces cerevisiae, Brettanomyces bruxellensis, Kloeckera apiculata among others) can produce histamine, ethanolamine, agmatine, phenylethylamine and cadaverine (Caruso et al., 2002; Torrea and Ancín, 2002; VidalCarou et al., 1990; Pogorzelski, 1992; Buteau et al., 1984).

For the determination of BAs in foodstuffs diverse methods have been proposed in the bibliography, among them high performance liquid chromatography followed by fluorimetric detection or spectrophotometry is the most commonly used technique in recent years, especially for the analysis of wines (Busto et al., 1996; Soufleros et al., 1998; Glória et al., 1998; Soleas et al., 1999). Recently the application of more complex methods of detection, such as mass spectrometry, have also begun to be used (Loukou and Zotou, 2003). Due to the complexity of wine, generally the analysis of BAs is accompanied by the use of techniques of pre or post column derivatisation, which permit a significant advance in the sensitivity on eliminating interferences. Among the different reagents used are: dansyl chloride (Csomos and Simonne, 2002; Anli et al., 2004; Caruso et al., 2002), o-phthalaldehyde (Herbert et al., 2001, 2004; Glória et al., 1998; Iñiguez-Crespo and VázquezLasa, 1994; Busto et al., 1997; Mafra et al., 1999; Vidal-Carou et al., 2003; Leitão et al., 2005; Moreno-Arribas et al., 2003; Martínez et al., 2000; Lavizzari et al., 2006; Del Prete et al., 2009), dabsyl chloride (Romero et al., 2000; Romero et al., 2002) and 6aminoquinolyl-N-hydroxysuccinimidyl carbamate (Jiménez-Moreno et al., 2003; Torrea and Ancín, 2001; Torrea and Ancín, 2002; Martínez et al., 2000).

Of all of them, o-phthalaldehyde (OPA) is most habitual. Its principal advantages being it offers high selectivity and sensitivity for the primary amines (Izquierdo-Pulido et al., 1993), as well as the fact that the reaction of derivatisation is performed in a short period of time, thus preventing errors associated with long manipulations.

In this work the determination of BAs in quality wines of Castilla y León (Spain) has been carried out by HPLC using derivatisation with o-phthalaldehyde. For this, the principal variables involved in the derivatisation reaction and chromatographic separation were initially studied. The method developed was validated in terms of precision, repeatability and linearity. With the aim of contributing to the knowledge of the origin and evolution of BAs in wines, the analytical method has been applied to the determination of BAs during the winemaking process of quality red wines from the Spanish "Denominación de Origen" (DO) Toro, including an organic wine, as well as other DO wines from the "Comunidad Autónoma de Castilla y León" (Spain).

\section{Materials and methods}

\subsection{Standard and reagents}

The biogenic amines cadaverine (Cad), agmatine ( $\mathrm{Ag}$ ), ethylamine (Et), isobutylamine (Iso), phenylethylamine (Phe), putrescine (Put), and isoamylamine (Isoa) were supplied by Sigma-Aldrich (Steinheim, Germany); serotonin (Ser), histamine (His), tyramine (Tyr) and tryptamine (Tryp) by Merck (Darmstad, Germany). The internal standard (IS), L-norvaline, was supplied by Sigma-Aldrich (Steinheim, Germany). o-Phthalaldehyde (OPA), from Merck, Darmstadt, Germany, was used as the derivatisation reagent.

The preparation of the OPA was performed weekly from $500 \mathrm{mg}$ of o-phthalaldehyde and $22.5 \mathrm{~mL}$ of methanol in $25 \mathrm{~mL}$ of borate buffer $0.4 \mathrm{M} \mathrm{pH} \mathrm{10,} \mathrm{with} \mathrm{the} \mathrm{final} \mathrm{addition} \mathrm{of} 400 \mu \mathrm{L}$ of mercaptoethanol.

All the reagents used were of HPLC quality. The ultra-pure water of HPLC grade was obtained using a MilliQ-alpha MillporeWaters system (Bedford, MA).

\subsection{Samples}

For the study of the evolution in the content of BAs during the elaboration of quality wines, Vitis vinifera L. cv Toro fresh grapes processed by wineries from the Spanish DO Toro were used. Wine made from organically certified vineyards, organic wine (OW), was obtained by regulated winemaking methods. The wine corresponding to the first fraction obtained through a direct pressing pomace, quality press wine (QPW), and the free run wine, quality wine $(\mathrm{QW})$, were inoculated with selected yeast and malolactic bacteria. Samples were taken during the winemaking and maturation process and are summarised in Table 1.

Three sub-samples were taken from each step, and their analyses were performed in triplicate. All samples were immediately stabilised with sodium fluoride and stored in refrigeration 
until their analysis in the laboratory. Moreover, 28 Spanish red wines were analysed (Table 5) belonging to different DO's of Castilla y León (Ribera de Duero, Vinos de la Tierra de Castilla y León, Bierzo, Cigales and Vino de Calidad de Arribes). These wines were acquired in the market. The analyses were performed in triplicate.

\subsection{Preparation of standard and wine samples}

Both the samples of wine and the standard solutions were filtered through $0.45 \mu \mathrm{m}$ filters. $1000 \mu \mathrm{L}$ of filtrate were mixed with $800 \mu \mathrm{L}$ of borate buffer $0.4 \mathrm{M}$ (pH 10) and $200 \mu \mathrm{L}$ of the solution of the I.S. (L-norvaline, $100 \mathrm{mg} / \mathrm{L}$ ). $300 \mu \mathrm{L}$ of the solution obtained were later mixed automatically in the injector with $100 \mu \mathrm{L}$ of derivatisation reagent (OPA). After the reaction time (one minute) $10 \mu \mathrm{L}$ of the mixture were automatically injected into the chromatographic system for their analysis. All the analyses were performed in triplicate.

\subsection{Analysis by HPLC}

Analyses were performed with a Varian HPLC equipped with a 9012Q quaternary pump, a 9100 automatic injector, a 9075 fluorescence detector and using a Synergi-Hydro ${ }^{\circledR} \mathrm{RP}-80 \AA$ A column with a particle size of $4 \mu \mathrm{m}(150 \mathrm{~mm} \times 4.6 \mathrm{~mm})$ (Phenomenex, Torrance, CA). The system was controlled by a Varian Star Workstation version 5.52. Chromatographic conditions were: solvent $(\mathrm{A})$ : sodium acetate $0.05 \mathrm{M}$ adjusted to $\mathrm{pH}$ 6.6/tetrahydrofurane (99:1); solvent (B): methanol/acetonitrile (50:50).

The elution gradient established was: isocratic $40 \%$ B for $5 \mathrm{~min}$, $40-50 \%$ B for 9 min, $50-60 \%$ B for $12 \mathrm{~min}, 60-75 \%$ B for $16 \mathrm{~min}, 75-$ $85 \%$ B for $3 \mathrm{~min}$ and $85-100 \%$ B for $1 \mathrm{~min}$, at a flow rate of $1 \mathrm{~mL} /$ min. Detection was carried out at $340 \mathrm{~nm}$ and $426 \mathrm{~nm}$ as excitation and emission wavelengths, respectively. For the quantitative analysis, linear calibration curves of each biogenic amine were obtained in the concentration range $1-30 \mathrm{mg} / \mathrm{L}$.

\subsection{Statistical analysis}

For comparison of wines, data were presented as mean \pm standard deviation $(S D)$ of analyses performed in triplicate. Statistical bilateral correlation studies, with the correlation coefficient of Pearson (significance $P<0.05$ ), were carried out using SPSS 13.0 statistical software.

\section{Results and discussion}

For method development, different internal standards (L-norvaline and 1,7-diaminoheptane) and solvent systems to dissolve the amines (ultrapure water acidified $0.1 \mathrm{~N}(\mathrm{pH} 3.6)$, borate buffer and acetate buffer at $\mathrm{pH} 10$ ), as well as different eluents for the chromatographic runs (for phase A: sodium phosphate $10 \mathrm{mM} \mathrm{(pH}$ 7.3)-methanol-tetrahydrofurane $(80: 19: 1)$ and $\mathrm{Na}_{2} \mathrm{HPO}_{4} \cdot 12 \mathrm{H}_{2} \mathrm{O}$
$10 \mathrm{mM}$; and for phase B: sodium phosphate $10 \mathrm{mM}(\mathrm{pH} 7.3)-$ methanol (20:80) and $1 \%$-octanol in acetonitrile- $\mathrm{Na}_{2} \mathrm{HPO}_{4} \cdot 12 \mathrm{H}_{2} \mathrm{O}$ $10 \mathrm{mM}$ (70:30)), were assayed.

With the conditions selected (see Section 2) a good chromatographic separation of the peaks corresponding to the internal standard (L-norvaline) and to the 11 BAs studied (Ag, His, Ser, Et, Tyr, Isob, Tryp, Phe, Put, Isoa and Cad) was obtained in an acceptable elution time. Fig. 1 shows chromatograms corresponding to a biogenic amine standard solution of $10 \mathrm{mg} / \mathrm{L}$ and to a red wine sample.

\subsection{Figures of merit}

The method proposed was validated in terms of linearity, precision, coefficient of variation and recovery. The limits of detection and quantification of the amines were calculated.

The equations of regression, coefficients of determination and the ranges of linearity for the 11 compounds analysed are presented in Table 2 . The goodness of fit of the regression model was also evaluated by the $F$-test. For this, regression variance and residual variance were obtained by means of an ANOVA analyse. The $p$-values in the $F$-test were lower than 0.05 indicating significance. Also, the lack of fit F-test was performed. For this, the lack of fit and the pure error were obtained by means of an ANOVA analysis of the residual variance. The $p$-values obtained were greater than 0.1 , indicating that the fitted equation is statistically valid. The linear range of the response obtained is sufficient in all the amines considered, no amine being found in quantity superior to the upper limit in the samples. Furthermore, the limits of detection (LODs) and quantification (LOQs) were studied.

The limits of detection were calculated under the Glaser criteria (Glaser et al., 1981). LOD $=t(N-1,1-\alpha=0.99) \times S D$, where $t(N-1,1-\alpha=0.99)$ is the Student $t$-value for a one-tailed test at the $99 \%$ confidence level with $N-1$ degrees of freedom. $S D$ is the standard deviation of seven replicate analyses with concentrations from twice to five fold the estimated LOD according to the relationship between the instrumental signal/noise. The LOQs were three times the LODs. The limits of detection of the amines studied lies within an interval between 0.015 and $0.110 \mathrm{mg} / \mathrm{L}$ and the limits of quantification between 0.046 and $0.331 \mathrm{mg} / \mathrm{L}$ (Table 2).

Repeatability and recovery of the method were also determined (Table 3). Both parameters were calculated by carrying out seven consecutive injections of the standards of BAs at three different concentrations $(1,10,25 \mathrm{mg} / \mathrm{L})$ in the selected conditions.

The repeatability was expressed as the coefficient of variation (\%) and the calculation was based on $(S D / x) \times 100$, where $S D$ is the relative standard deviation and $x$ is the mean of the different injections. The percentage of repeatability for low concentrations $(1 \mathrm{mg} / \mathrm{L})$ varied between 3.09 and $8.66 \%$, for medium concentrations $(10 \mathrm{mg} / \mathrm{L})$ between 2.09 and 4.89 and for high concentrations $(25 \mathrm{mg} / \mathrm{L})$ between 2.96 and $6.28 \%$.

Table 1

Samples taken in QW, QPW and OW wines.

\begin{tabular}{lrrr}
\hline & Samples & QW & QPW \\
\hline Step 1 & Grape must & $20 / 09 / 2005$ & - \\
Step 2 & End alcoholic fermentation & $10 / 10 / 2005$ & - \\
Step 3 & Before malolactic fermentation & $24 / 10 / 2005$ & - \\
Step 4 & End malolactic fermentation & $16 / 11 / 2005$ & $24 / 10 / 2005$ \\
Step 5 & First racking & $24 / 01 / 2006$ & $16 / 11 / 2005$ \\
Step 6 & One month in oak barrel & $24 / 02 / 2006$ & - \\
Step 7 & QW/OW & $24 / 03 / 2006$ & - \\
Step 8 & QW/OW & $24 / 04 / 2006$ & - \\
\hline
\end{tabular}

7 QW: two months m oak barrel; 7 oW: before bottling.

$8 \mathrm{QW}$ : three months in oak barrel; 8 OW: one month in bottle. 
Table 2

Regression analysis equations, coefficients of determination (R), limits of detection (LODs) and quantification (LOQs), precision and linear ranges of the method for determination of biogenic amines in wine.

\begin{tabular}{|c|c|c|c|c|c|c|}
\hline Compounds & Regression equation $y=\left(a \pm S D_{a}\right)+\left(b \pm S D_{b}\right) x$ & $R^{2}$ & LODs $(\mathrm{mg} / \mathrm{L})^{\mathrm{a}}$ & LOQs $(\mathrm{mg} / \mathrm{L})^{\mathrm{b}}$ & Precision $( \pm S D)$ & Linear range $(\mathrm{mg} / \mathrm{L})$ \\
\hline Agmatine & $y=(-0.01 \pm 0.04)+(0.36 \pm 0.02) x$ & 0.998 & 0.066 & 0.197 & 0.021 & $0.066-30$ \\
\hline Isoamylamine & $y=(0.04 \pm 0.04)+(0.61 \pm 0.03) x$ & 0.994 & 0.029 & 0.086 & 0.009 & $0.029-25$ \\
\hline Putrescine & $y=(-0.03 \pm 0.04)+(0.39 \pm 0.02) x$ & 0.995 & 0.038 & 0.113 & 0.012 & $0.038-30$ \\
\hline Isobutylamine & $y=(0.08 \pm 0.07)+(0.57 \pm 0.04) x$ & 0.991 & 0.085 & 0.254 & 0.027 & $0.085-25$ \\
\hline Cadaverine & $y=(0.01 \pm 0.09)+(0.57 \pm 0.05) x$ & 0.995 & 0.023 & 0.069 & 0.007 & $0.023-30$ \\
\hline Histamine & $y=(-0.01 \pm 0.04)+(0.42 \pm 0.02) x$ & 0.998 & 0.068 & 0.203 & 0.022 & $0.068-30$ \\
\hline Serotonin & $y=(-0.01 \pm 0.01)+(0.11 \pm 0.01) x$ & 0.995 & 0.094 & 0.282 & 0.030 & $0.094-30$ \\
\hline Tryptamine & $y=(-0.04 \pm 0.03)+(0.39 \pm 0.02) x$ & 0.998 & 0.015 & 0.046 & 0.005 & $0.015-30$ \\
\hline Ethylamine & $y=(0.07 \pm 0.05)+(0.47 \pm 0.03) x$ & 0.996 & 0.110 & 0.331 & 0.035 & $0.110-30$ \\
\hline Tyramine & $y=(-0.02 \pm 0.05)+(0.47 \pm 0.03) x$ & 0.997 & 0.025 & 0.075 & 0.008 & $0.025-30$ \\
\hline Phenylethylamine & $y=(0.04 \pm 0.06)+(0.56 \pm 0.04) x$ & 0.991 & 0.040 & 0.121 & 0.013 & $0.040-25$ \\
\hline
\end{tabular}

$y$, peak area ratio of each biogenic amine to internal standard (mean of three determinations); $x$, concentration in $\mathrm{mg} / \mathrm{L} ; a$, intercept; $b$, slope; $S D_{a}$ and $S D_{b}$, standard deviations of intercept and slope, respectively.

a Limit of detection $(\mathrm{mg} / \mathrm{L})$.

b Limit of quantification $(\mathrm{mg} / \mathrm{L})$

The recovery was calculated by comparison of the initial concentration of the sample with that obtained after injection. The percentages of recovery obtained at low concentration $(1 \mathrm{mg} / \mathrm{L})$ varied from 56 to $108 \%$, at medium concentration $(10 \mathrm{mg} / \mathrm{L})$ from 83 to $117 \%$ and at high concentration $(25 \mathrm{mg} / \mathrm{L})$ was situated between 104 and 109\%. The lowest values of recovery were those obtained at low concentration $(1 \mathrm{mg} / \mathrm{L})$ for Tryp and Cad, in which it was situated below 60\%. The His, a biogenic amine of great interest, presents very good proportions of recovery (from 93 to $104 \%$ ) at the three concentrations studied.

\subsection{Application to wine samples}

The method was used for the determination of BAs in samples of quality wines collected during the winemaking process from the Spanish DO Toro. The average value of BAs in the analysed samples is reported in Table 4. His, Et, Put and Cad were found both in organic and non-organic wine. Tyr, Phe and Tryp were only present in the samples of OW wine. The amines Ag, Ser, Isob and Isoa were not found in quantifiable concentrations in any of the wines.

In the QW wine, the sample corresponding to grape must already contains BAs $(8.35 \mathrm{mg} / \mathrm{L})$ and this content tends to increase
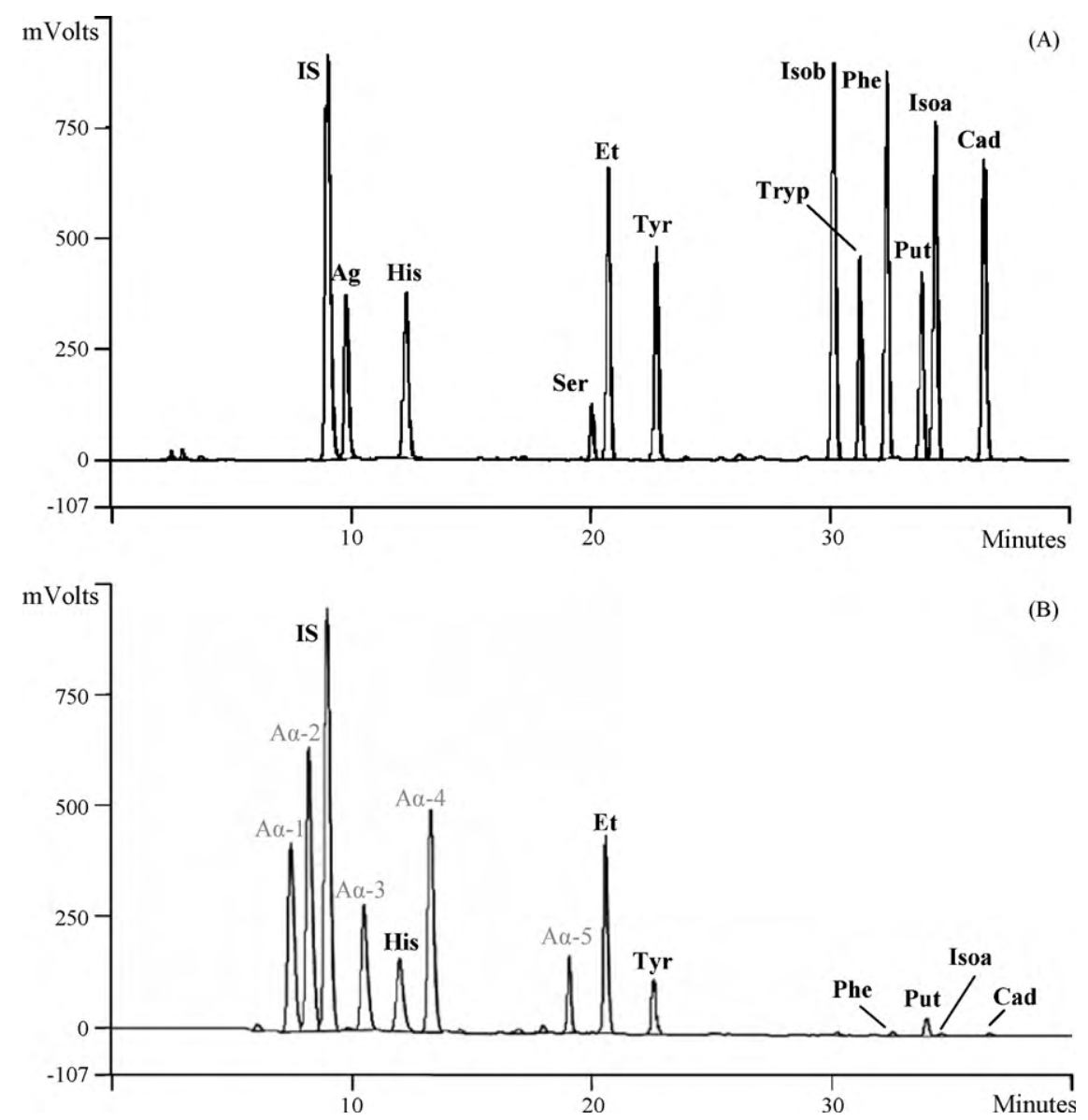

Fig. 1. Chromatograms corresponding to a biogenic amine standard solution of $10 \mathrm{mg} / \mathrm{L}(\mathrm{A})$ and to a red wine sample (B). A $\alpha-1$ to $A \alpha-5$ are wine amino acids. 
Table 3

Coefficient of variation (CV\%) and recovery of the standards of biogenic amines at low (1 mg/L), medium (10 mg/L) and high (25 mg/L) concentrations.

\begin{tabular}{|c|c|c|c|c|c|c|}
\hline \multirow[t]{2}{*}{ Compounds } & \multicolumn{3}{|c|}{$\mathrm{CV}(\%, n=7)$} & \multicolumn{3}{|c|}{ Recovery $(\%) \pm \mathrm{SD}^{\mathrm{a}}(n=7)$} \\
\hline & Low $^{\mathrm{b}}$ & Medium $^{\mathrm{c}}$ & $\overline{\text { High }^{d}}$ & Low $^{b}$ & Medium $^{c}$ & $\operatorname{High}^{\mathrm{d}}$ \\
\hline Agmatine & 4.756 & 2.904 & 3.734 & $89 \pm 4$ & $98 \pm 3$ & $104 \pm 4$ \\
\hline Isoamylamine & 6.755 & 3.940 & 3.096 & $108 \pm 7$ & $116 \pm 5$ & $103 \pm 3$ \\
\hline Putrescine & 8.340 & 4.895 & 6.280 & $72 \pm 4$ & $95 \pm 5$ & $105 \pm 7$ \\
\hline Isobutylamine & 8.666 & 3.338 & 3.548 & $91 \pm 17$ & $104 \pm 5$ & $109 \pm 4$ \\
\hline Cadaverine & 7.721 & 3.150 & 3.812 & $56 \pm 2$ & $115 \pm 4$ & $105 \pm 4$ \\
\hline Histamine & 3.672 & 2.371 & 3.863 & $93 \pm 3$ & $99 \pm 2$ & $104 \pm 4$ \\
\hline Serotonin & 8.207 & 4.149 & 5.778 & $64 \pm 5$ & $83 \pm 3$ & $114 \pm 7$ \\
\hline Tryptamine & 4.679 & 3.330 & 5.576 & $59 \pm 3$ & $87 \pm 3$ & $105 \pm 6$ \\
\hline Ethylamine & 3.520 & 3.307 & 2.960 & $63 \pm 9$ & $117 \pm 4$ & $109 \pm 3$ \\
\hline Tyramine & 3.089 & 2.094 & 4.386 & $88 \pm 3$ & $95 \pm 2$ & $104 \pm 5$ \\
\hline Phenylethylamine & 4.341 & 2.400 & 3.372 & $99 \pm 4$ & $127 \pm 3$ & $106 \pm 4$ \\
\hline
\end{tabular}

a Standard deviation.

b Low concentration: $1 \mathrm{mg} / \mathrm{L}$.

c Medium concentration: $10 \mathrm{mg} / \mathrm{L}$.

d High concentration: $25 \mathrm{mg} / \mathrm{L}$.

throughout winemaking and maturation (Fig. 2). Some authors have reported the presence of ethanolamine, spermidine, Et, Put and His in grapes and musts (Del Prete et al., 2009; Broquedis et al., 1989; Vidal-Carou et al., 1990; Ough and Daudt, 1981; Broquedis et al., 1989) and it has been postulated that the variety of the grape,
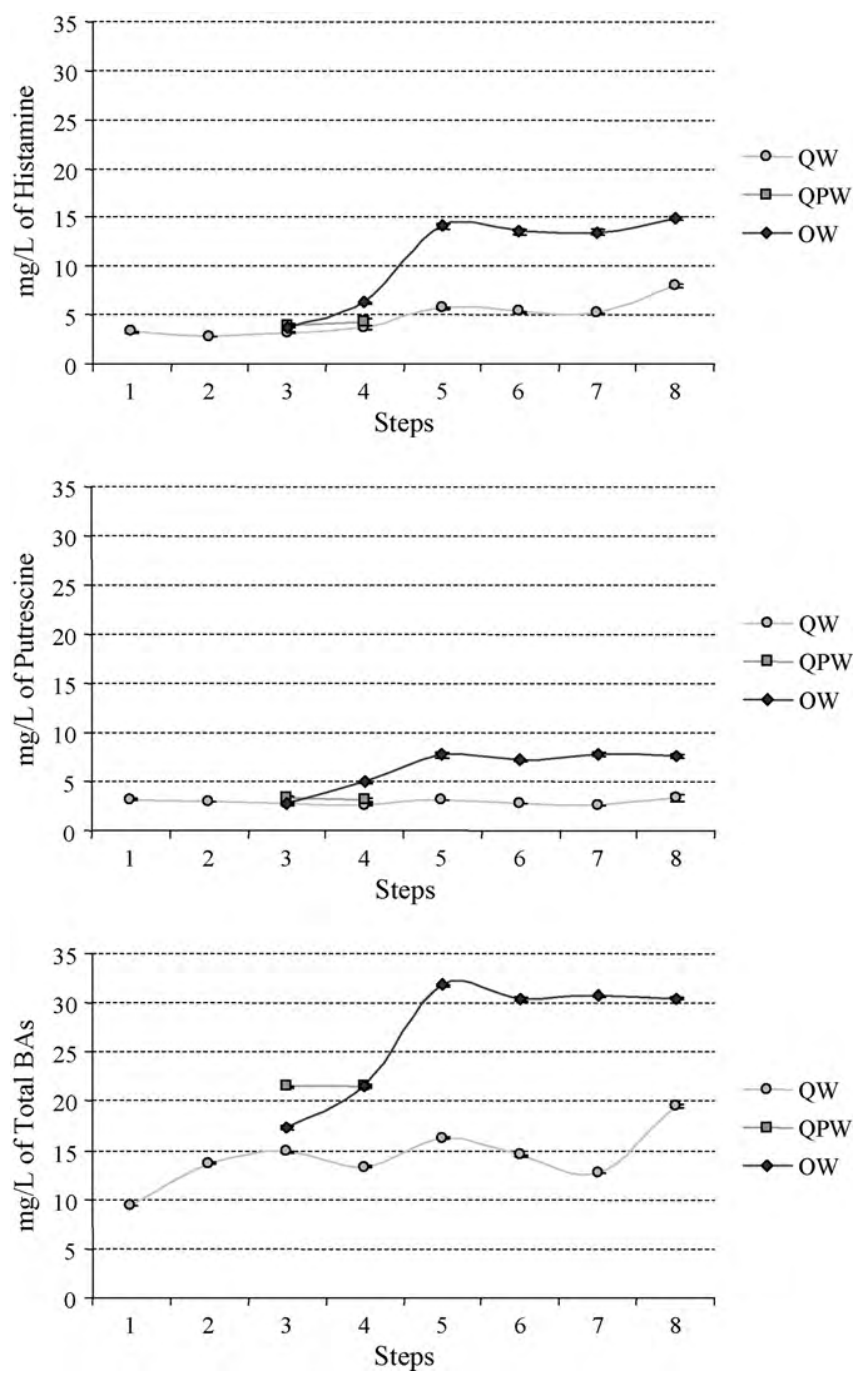

Fig. 2. Evolution of the contents of histamine, putrescine and total BAs during winemaking. vine nutrition and the climatic conditions play a role in the accumulation of these compounds (Soufleros et al., 1998; LonvaudFunel, 2001; Del Prete et al., 2009).

The greatest increases in BAs in QW correspond to the AF (step 2) and to the last step of the maturation process sampled (step 8). The notable increase observed after the AF can be explained by the fact that several S. cerevisiae strains can produce significant levels of BAs (Caruso et al., 2002; Torrea and Ancín, 2002) and in our study is due to the important increase produced in Et. This result is contrary to that obtained by Del Prete et al. (2009) who found that this amine diminishes during the $A F$, possibly due to its incorporation by the fermentation yeasts to their metabolism.

In our case, the increase in the content of this amine in the wine also seems linked to the contact of the wine with the solids of winemaking, since the pressed wine (QPW) has much higher contents than the QW wine considering the same stages of winemaking (steps 3 and 4).

After MLF no appearance of new amines was observed and there was no increase in their total content during MLF, probably because the selected lactic bacteria were inoculated. Only a significant, though slight, increase in His was observed.

During maturation (steps 5-8), a decrease in the BAs content can be observed in the samples except in the last step (step 8). This step coincides with the addition of yeast mannoproteins, which is why we think that this practice could be responsible for the increase observed, since it would permit an increase in the content of nitrogen compounds which, probably, in the presence of residual enzyme activity, could act as precursors for the BAs synthesis.

QPW is the press wine obtained from QW pomace. We can observe in Table 4 and in Fig. 2 that (for the same step), press wine has higher levels of BAs than the free run wine ( $27 \%$ more). This wine is added to QW after MLF and that may be why the levels of BAs in QW increase from step 4 to step 5. Nevertheless, the contents in Et in step 5 of the QW wine are lower than expected, considering the concentration of this amine in the QPW wine, although this could be due to the fact that Et is an aromatic amine and, therefore, volatile.

In the OW wine, the MLF exerts a remarkable effect in the BAs' content. In contrast to QW, OW was not inoculated with selected lactic bacteria, because it is subject to organic wine restrictions and in this wine MLF occurs spontaneously.

His, Et and Put are the most abundant BAs in all samples. His content is relatively elevated in $\mathrm{OW}$, being higher than in $\mathrm{QW}$ (Fig. 2). A great increase of this amine in OW is produced after MLF (steps 4 and 5), which is accompanied by the emerging of other amines: Tyr, Tryp, Phe, absent in QW. The increase in the BAs' levels 
Table 4

Quantification of biogenic amines in wine samples $(\mathrm{mg} / \mathrm{L})$ during winemaking.

\begin{tabular}{|c|c|c|c|c|c|c|c|c|c|c|c|c|}
\hline & $\mathrm{Ag}$ & His & Ser & Et & Tyr & Isob & Tryp & Phe & Put & Isoa & Cad & Total \\
\hline \multicolumn{13}{|c|}{ Quality wine (QW) } \\
\hline Step 1 & $n c$ & $3.26 \pm 0.16^{\mathrm{b} / \mathrm{A}}$ & nd & $1.03 \pm 0.06^{\mathrm{a} / \mathrm{A}}$ & $0.00 \pm 0.00^{-1-}$ & $n c$ & $0.00 \pm 0.00^{-1-}$ & $0.00 \pm 0.00^{-1-}$ & $3.21 \pm 0.09^{\mathrm{de} / \mathrm{A}}$ & $n c$ & $0.85 \pm 0.07^{\mathrm{a} / \mathrm{A}}$ & $8.35 \pm 0.08^{\mathrm{a} / \mathrm{A}}$ \\
\hline Step 2 & $n c$ & $2.79 \pm 0.05^{\mathrm{a} / \mathrm{A}}$ & nd & $5.44 \pm 0.16^{\mathrm{c} / \mathrm{A}}$ & $0.00 \pm 0.00^{-1-}$ & $n c$ & $0.00 \pm 0.00^{-1-}$ & $0.00 \pm 0.00^{-1-}$ & $2.97 \pm 0.06^{\mathrm{bcd} / \mathrm{A}}$ & $n c$ & $1.96 \pm 0.01^{\mathrm{c} / \mathrm{A}}$ & $13.17 \pm 0.08^{\mathrm{c} / \mathrm{A}}$ \\
\hline Step 3 & $n c$ & $3.25 \pm 0.01^{\mathrm{b} / \mathrm{A}}$ & nd & $6.29 \pm 0.09^{\mathrm{d} / \mathrm{A}}$ & $0.00 \pm 0.00^{-1-}$ & $n c$ & $0.00 \pm 0.00^{-1-}$ & $0.00 \pm 0.00^{-1-}$ & $2.80 \pm 0.03^{\mathrm{abc} / \mathrm{AB}}$ & $n c$ & $1.93 \pm 0.01^{\mathrm{c} / \mathrm{B}}$ & $14.27 \pm 0.05^{\mathrm{e} / \mathrm{A}}$ \\
\hline Step 4 & $n c$ & $3.78 \pm 0.20^{\mathrm{c} / \mathrm{A}}$ & nd & $6.31 \pm 0.12^{\mathrm{d} / \mathrm{A}}$ & $0.00 \pm 0.00^{-l-}$ & $n c$ & $0.00 \pm 0.00^{-l-}$ & $0.00 \pm 0.00^{-1-}$ & $2.68 \pm 0.01^{\mathrm{ab} / \mathrm{A}}$ & $n c$ & $0.00 \pm 0.00^{-1-}$ & $12.77 \pm 0.10^{\mathrm{c} / \mathrm{A}}$ \\
\hline Step 5 & $n c$ & $5.68 \pm 0.06^{\mathrm{e} / \mathrm{A}}$ & nd & $6.18 \pm 0.08^{\mathrm{d} / \mathrm{B}}$ & $0.00 \pm 0.00^{-1-}$ & $n c$ & $0.00 \pm 0.00^{-1-}$ & $0.00 \pm 0.00^{-1-}$ & $3.12 \pm 0.04^{\text {cde } / \mathrm{A}}$ & $n c$ & $1.30 \pm 0.05^{\mathrm{b} / \mathrm{A}}$ & $16.27 \pm 0.06^{\mathrm{f} / \mathrm{A}}$ \\
\hline Step 6 & $n c$ & $5.31 \pm 0.16^{\mathrm{de} / \mathrm{A}}$ & nd & $5.22 \pm 0.11^{\mathrm{bc} / \mathrm{B}}$ & $0.00 \pm 0.00^{-1-}$ & $n c$ & $0.00 \pm 0.00^{-1-}$ & $0.00 \pm 0.00^{-1-}$ & $2.72 \pm 0.03^{\mathrm{ab} / \mathrm{A}}$ & $n c$ & $1.30 \pm 0.06^{\mathrm{b} / \mathrm{B}}$ & $14.54 \pm 0.09^{\mathrm{d} / \mathrm{A}}$ \\
\hline Step 7 & $n c$ & 5.21 & nd & $4.84 \pm 0.14^{\mathrm{b} / \mathrm{A}}$ & $0.00 \pm 0.00^{-I-}$ & $n c$ & $0.00 \pm 0.00^{-I-}$ & $0.00 \pm 0.00^{-I-}$ & $2.64 \pm 0.03^{\mathrm{a} / \mathrm{A}}$ & $n c$ & $0.00 \pm 0.00^{-1-}$ & $12.69 \pm 0.07^{\mathrm{b} / \mathrm{A}}$ \\
\hline Step 8 & $n c$ & $8.02 \pm 0.20^{\mathrm{f} / \mathrm{A}}$ & nd & $6.18 \pm 0.27^{\mathrm{d} / \mathrm{A}}$ & $0.00 \pm 0.00^{-1-}$ & $n c$ & $0.00 \pm 0.00^{-1-}$ & $0.00 \pm 0.00^{-1-}$ & $3.35 \pm 0.30^{\mathrm{e} / \mathrm{A}}$ & $n c$ & $1.98 \pm$ & $19.52 \pm 0.20^{\mathrm{g} / \mathrm{A}}$ \\
\hline \multicolumn{13}{|c|}{ Quality press wine (QPW) } \\
\hline Step 3 & $n c$ & $4.00 \pm 0.13^{\mathrm{a} / \mathrm{B}}$ & nd & $11.04=$ & $0.00 \pm 0.00^{-/-}$ & $n c$ & $0.00 \pm 0.00^{-1-}$ & $0.00 \pm 0.00$ & $3.25 \pm 0.24^{\mathrm{a} / \mathrm{B}}$ & $n c$ & $2.05 \pm 0.10^{\mathrm{a} / \mathrm{B}}$ & $20.34 \pm 0.12^{\mathrm{a} / \mathrm{C}}$ \\
\hline Step 4 & $n c$ & $4.27 \pm 0.31^{\mathrm{a} / \mathrm{A}}$ & nd & $10.90 \pm 0.14^{\mathrm{a} / \mathrm{C}}$ & $0.00 \pm 0.00^{-1-}$ & $n c$ & $0.00 \pm 0.00^{-1-}$ & $0.00=$ & $3.14 \pm 0.13^{\mathrm{a} / \mathrm{B}}$ & $n c$ & $2.02 \pm 0.09^{\mathrm{a} / \mathrm{B}}$ & $20.33 \pm 0.14^{\mathrm{a} / \mathrm{B}}$ \\
\hline \multicolumn{13}{|c|}{ Organic wine (OW) } \\
\hline Step 3 & $n c$ & $3.78 \pm 0.13^{\mathrm{a} / \mathrm{B}}$ & nd & $9.23 \pm 0.30^{\mathrm{c} / \mathrm{B}}$ & $0.00 \pm 0.00^{-I-}$ & $n c$ & $0.00 \pm 0.00^{-1-}$ & $0.00 \pm 0.00^{-1-}$ & $2.78 \pm 0.21^{\mathrm{a} / \mathrm{A}}$ & $n c$ & $0.65 \pm 0.13^{\mathrm{a} / \mathrm{A}}$ & $16.44 \pm 0.16^{\mathrm{a} / \mathrm{B}}$ \\
\hline Step 4 & $n c$ & $6.24 \pm 0.02^{\mathrm{b} / \mathrm{B}}$ & nd & $9.00 \pm 0.10^{\mathrm{c} / \mathrm{B}}$ & $0.00 \pm 0.00^{-1-}$ & $n c$ & $0.00 \pm 0.00^{-1-}$ & $0.00 \pm$ & $4.93 \pm 0.11^{\mathrm{b} / \mathrm{C}}$ & $n c$ & $0.65 \pm 0.12^{\mathrm{a} / \mathrm{A}}$ & $20.81 \pm 0.07^{\mathrm{b} / \mathrm{B}}$ \\
\hline Step 5 & $n c$ & $14.10 \pm 0.31^{\mathrm{d} / \mathrm{B}}$ & nd & $4.54 \pm 0.03^{\mathrm{a} / \mathrm{A}}$ & $2.71 \pm 0.07^{\mathrm{b} / \mathrm{A}}$ & $n c$ & $0.60 \pm 0.03^{\mathrm{a} / \mathrm{A}}$ & $0.06 \pm 0.01^{\mathrm{a} / \mathrm{A}}$ & $7.71 \pm 0.30^{\mathrm{d} / \mathrm{B}}$ & $n c$ & $1.30 \pm 0.12^{\mathrm{b} / \mathrm{B}}$ & $31.02 \pm 0.11^{\mathrm{d} / \mathrm{B}}$ \\
\hline Step 6 & $n c$ & $13.54 \pm 0.25^{\mathrm{c} / \mathrm{B}}$ & nd & $4.75 \pm 0.20^{\mathrm{a} / \mathrm{A}}$ & $2.85 \pm 0.20^{\mathrm{b} / \mathrm{A}}$ & $n c$ & $0.60 \pm 0.04^{\mathrm{a} / \mathrm{A}}$ & $0.06 \pm 0.01^{\mathrm{a} / \mathrm{A}}$ & $7.13 \pm 0.10^{\mathrm{c} / \mathrm{B}}$ & $n c$ & $0.66 \pm 0.13^{\mathrm{a} / \mathrm{A}}$ & $29.58 \pm 0.13^{\mathrm{c} / \mathrm{B}}$ \\
\hline Step 7 & $n c$ & $13.48 \pm 0.30^{\mathrm{c} / \mathrm{B}}$ & nd & $4.78 \pm 0.08^{\mathrm{a} / \mathrm{A}}$ & $1.87 \pm 0.21^{\mathrm{a} / \mathrm{A}}$ & $n c$ & $0.60 \pm 0.04^{\mathrm{a} / \mathrm{A}}$ & $0.06 \pm 0.01^{\mathrm{a} / \mathrm{A}}$ & $7.78 \pm 0.21^{\mathrm{d} / \mathrm{B}}$ & $n c$ & $1.30 \pm 0.12^{\mathrm{b} / \mathrm{A}}$ & $29.86 \pm 0.13^{\mathrm{c} / \mathrm{B}}$ \\
\hline Step 8 & $n c$ & $14.94 \pm 0.19^{\mathrm{e} / \mathrm{B}}$ & nd & $5.27 \pm 0.20^{\mathrm{b} / \mathrm{A}}$ & $2.57 \pm 0.08^{\mathrm{b} / \mathrm{A}}$ & $n c$ & $0.00 \pm 0.00^{-1-}$ & $0.13 \pm 0.02^{\mathrm{b} / \mathrm{A}}$ & $7.56 \pm 0.20^{\mathrm{cd} / \mathrm{B}}$ & $n c$ & $0.00 \pm 0.00^{-1-}$ & $30.46 \pm 0.14^{\mathrm{c} / \mathrm{A}}$ \\
\hline
\end{tabular}

For each step, data are the mean \pm S.D. of 3 sub-samples analysed in triplicate. Different lower case letters indicate significant differences $(P<0.05)$ between steps for each wine. Different upper case letters indicate significant differences $(P<0.05)$ between wines for each step. nd: non-detectable; nc: non-quantifiable.

in OW samples can, therefore, be attributed to the fact that MLF happens spontaneously. In addition, it should be noted that at this step, the $\mathrm{pH}$ was higher in OW than in QW (3.6 and 3.3, respectively) and in these conditions both the number and type of bacterial microflora increase and the protective activity of $\mathrm{SO}_{2}$ decreases. Another amine with an important quantitative presence in the samples is Et. The level of this amine grows in QW after AF and the highest level in OW and QPW is before MLF, which seems to indicate that in the samples analysed its presence is linked to the development of the AF more than to MLF.

Regarding Put, this amine was present in the samples of QW and OW obtained before MLF (Fig. 2). The noticeable increase that was detected in OW samples shows that spontaneous MLF is a factor that could enhance its content. The content of Cad evolves irregularly during the study and no tendency which allowed us to elucidate its possible origin was found. Similar observations have been made by other authors (Lonvaud-Funel, 2001) who indicate that Cad is already present in grape must and is produced and degraded during winemaking.

Tyr, Tryp and Phe were only detected in samples from OW after the MLF, which is why its presence could be linked to the spontaneous MLF. The low levels of $\mathrm{SO}_{2}$ in organic wines, due to legal impositions, could be responsible for not only the presence of these last amines but also the highest levels in total BAs found in OW.

The method was also used for the study of BAs in samples of commercial wines of different denominations of origin of the Comunidad Autónoma de Castilla y León (Table 5). His, Et Tyr and Put were found in all the wines analysed.

Table 5

Concentration $(\mathrm{mg} / \mathrm{L})$ of individual biogenic amines in samples of commercial wines.

\begin{tabular}{|c|c|c|c|c|c|c|c|c|c|c|c|c|c|}
\hline Wines & $\mathrm{Ag}$ & His & Ser & Et & Tyr & Isob & Tryp & Phe & Put & Isoa & Cad & Total & $\pm S D$ \\
\hline 1 & $n c$ & 6.66 & nd & 1.90 & 2.69 & $n c$ & $n c$ & $n c$ & 7.97 & $n c$ & 1.93 & 21.16 & 2.30 \\
\hline 2 & $n c$ & 8.86 & nd & 3.30 & 2.45 & $n c$ & $n c$ & $n c$ & 7.95 & $n c$ & $n c$ & 22.57 & 1.66 \\
\hline 3 & $n c$ & 6.50 & nd & 2.36 & 4.11 & $n c$ & $n c$ & $n c$ & 8.63 & $n c$ & 2.03 & 23.63 & 3.37 \\
\hline 4 & $n c$ & 5.46 & $n d$ & 2.37 & 1.79 & $n c$ & $n c$ & $n c$ & 5.55 & $n c$ & 1.90 & 17.08 & 1.57 \\
\hline 5 & $n c$ & 8.52 & nd & 2.58 & 3.60 & $n c$ & $n c$ & $n c$ & 11.09 & $n c$ & 1.96 & 27.76 & 1.09 \\
\hline 6 & $n c$ & 7.88 & nd & 2.35 & 2.01 & $n c$ & $n c$ & 0.23 & 8.88 & 0.67 & 1.96 & 25.89 & 0.60 \\
\hline 7 & $n c$ & 8.73 & nd & 3.33 & 4.40 & $n c$ & $n c$ & 0.36 & 18.50 & 0.85 & 1.97 & 40.07 & 0.00 \\
\hline 8 & $n c$ & 4.27 & $n d$ & 1.80 & 2.84 & $n c$ & $n c$ & 0.30 & 5.55 & 0.54 & 1.87 & 19.10 & 2.17 \\
\hline 9 & $n c$ & 4.99 & nd & 1.91 & 1.35 & $n c$ & $n c$ & 0.13 & 3.39 & 0.54 & 1.87 & 16.11 & 0.67 \\
\hline 10 & $n c$ & 4.04 & nd & 2.14 & 1.98 & $n c$ & $n c$ & 0.13 & 5.13 & 0.54 & 1.90 & 17.79 & 1.52 \\
\hline 11 & $n c$ & 4.73 & $n d$ & 2.17 & 1.90 & $n c$ & $n c$ & 0.13 & 3.31 & 0.54 & 1.87 & 16.57 & 0.50 \\
\hline 12 & $n c$ & 8.81 & $n d$ & 2.44 & 4.28 & $n c$ & $n c$ & 0.20 & 6.02 & 0.54 & 1.87 & 26.09 & 1.62 \\
\hline 13 & $n c$ & 5.47 & nd & 2.95 & 3.35 & $n c$ & $n c$ & 0.13 & 5.81 & 0.54 & 1.89 & 22.07 & 1.80 \\
\hline 14 & $n c$ & 4.81 & nd & 3.93 & 2.53 & $n c$ & $n c$ & 0.22 & 6.82 & 0.80 & 1.87 & 22.90 & 4.15 \\
\hline 15 & $n c$ & 6.71 & $n d$ & 3.31 & 3.19 & $n c$ & $n c$ & 0.16 & 8.32 & 0.54 & 1.91 & 26.06 & 3.88 \\
\hline 16 & $n c$ & 4.26 & $n d$ & 1.50 & 1.98 & $n c$ & $n c$ & 0.21 & 3.63 & 1.11 & 1.88 & 16.50 & 1.97 \\
\hline 17 & $n c$ & 4.95 & nd & 3.30 & 1.63 & $n c$ & $n c$ & 0.16 & 4.25 & 0.60 & 1.88 & 18.68 & 2.22 \\
\hline 18 & $n c$ & 8.76 & nd & 3.45 & 4.88 & $n c$ & $n c$ & 0.13 & 25.03 & 0.54 & 1.87 & 46.59 & 8.11 \\
\hline 19 & $n c$ & 3.10 & nd & 4.38 & 1.65 & $n c$ & $n c$ & $n c$ & 3.34 & $n c$ & $n c$ & 12.44 & 5.50 \\
\hline 20 & $n c$ & 1.72 & $n d$ & 3.00 & 1.32 & $n c$ & $n c$ & 0.18 & 1.16 & 0.21 & $n c$ & 7.51 & 2.00 \\
\hline 21 & $n c$ & 2.91 & nd & 3.59 & 3.11 & $n c$ & 0.25 & 0.10 & 1.95 & 0.31 & $n c$ & 12.07 & 4.17 \\
\hline 22 & $n c$ & 2.07 & nd & 3.16 & 1.17 & $n c$ & $n c$ & 0.24 & 0.98 & 0.52 & $n c$ & 8.07 & 2.14 \\
\hline 23 & $n c$ & 5.24 & $n d$ & 5.83 & 4.37 & $n c$ & $n c$ & $n c$ & 4.71 & $n c$ & $n c$ & 20.08 & 4.75 \\
\hline 24 & $n c$ & 2.80 & nd & 4.44 & 4.03 & $n c$ & $n c$ & 1.35 & 1.65 & 2.21 & $n c$ & 16.42 & 3.65 \\
\hline 25 & $n c$ & 3.30 & nd & 4.43 & 0.04 & $n c$ & $n c$ & 0.23 & 2.77 & 0.49 & $n c$ & 11.20 & 3.55 \\
\hline 26 & $n c$ & 5.24 & nd & 6.56 & 1.55 & $n c$ & $n c$ & $n c$ & 2.69 & 0.20 & $n c$ & 16.18 & 5.11 \\
\hline 27 & $n c$ & 3.21 & $n d$ & 6.66 & 4.44 & $n c$ & $n c$ & 0.69 & 0.51 & 0.72 & $n c$ & 16.16 & 2.57 \\
\hline 28 & $n c$ & 8.20 & nd & 5.95 & 0.48 & $n c$ & $n c$ & $n c$ & 3.54 & $n c$ & $n c$ & 17.97 & 4.06 \\
\hline
\end{tabular}

Data are the mean \pm SD of the samples analysed in triplicate. nd: non-detectable; nc: non-quantifiable. 
The amines Ag, Ser and Isob were not found in quantifiable concentrations in any of the wines. His, Put and Et were those which were found in highest concentrations, followed by Tyr, although its content was variable, depending on the wine. The concentration of His in the samples analysed varied between 1.72 and $8.86 \mathrm{mg} / \mathrm{L}$, Put between 0.51 and $25.03 \mathrm{mg} / \mathrm{L}$ and Et between 1.50 and $6.66 \mathrm{mg} / \mathrm{L}$. These concentrations lie within the range found by other authors who have analysed the content of these compounds in Spanish red wines (Bover-Cid et al., 2006; GarcíaVillar et al., 2007).

\section{Conclusions}

The main reasons why consumers choose organic food are concern for their health and for the environment. However, organic wines could have higher levels of BA than non-organic wines. This is probably due to the fact that MLF occurs spontaneously, and also due to the low levels of $\mathrm{SO}_{2}$ as a result of legal restrictions in organic wines. In non-organic wines, 2 oenological practices could increase the content in BA: the addition of press wine to the free run wine, and the treatment with yeast mannoproteins. On the one hand, the intense contact with the pomace, or solid parts of the grape, which the press wine undergoes, enhances the presence of BA. On the other hand, the addition of mannoproteins would permit an increase in the content of nitrogen compounds which, probably in the presence of residual enzyme activity, could act as precursors for the synthesis of BAs.

\section{Acknowledgements}

Financial support received from Junta de Castilla y Leon (Grant ref. SA050A05) and from Fundación Vinos de Zamora. Thanks are due to Mr. G.H. Jenkins for his help with the English version of the manuscript.

\section{References}

Anli, E.R., Vural, N., Yilmaz, S., Vural, Y.H., 2004. The determination of biogenic amines in Turkish red wines. Journal of Food Composition and Analysis 17, 5362.

Bauza, T., Blaise, A., Teissedre, P.L., Cabanis, J.C., Kanny, G., Moneret-Vautrin, D.A., Daumas, F., 1995. Biogenic amines. Metabolism and toxicity. Bulletin de l'O.I.V. $68,767-768$

Bover-Cid, S., Izquierdo-Pulido, M., Mariné-Font, A., Vidal-Carou, M.C., 2006. Biogenic mono-, di- and polyamine contents in Spanish wines and influence of a limited irrigation. Food Chemistry 96, 43-47.

Broquedis, M., Dumery, B., Boucard, J., 1989. Mise en èvidence de polyamines (putrescine, cadaverine, nor-spermidine, spermidine, spermin) dans les feuilles et les grapes de Vitis vinifera L. Connaiss Vigne Vin 23, 1-6.

Busto, O., Guasch, J., Borrull, F., 1996. Determination of biogenic amines in wine after precolumn derivatization with 6-aminoquinolyl-N-hydroxysuccinimidy carbamate. Journal of Chromatography A 737, 205-213.

Busto, O., Guasch, J., Borrull, F., 1997. Determination of biogenic amines in wines by high-performance liquid chromatography with on column fluorescence derivatization. Journal of Chromatography A 757, 311-318.

Buteau, C., Duitschaever, C.L., Ashton, G.C., 1984. High-performance liquid chromatographic detection and quantitation of amines in must and wine. Journal of Chromatography 284, 201-210.

Caruso, M., Fiore, C., Contursi, M., Salzano, G., Paparella, A., Romano, P., 2002. Formation of biogenic amines as criteria for the selection of wine yeasts. Journal of Microbiology and Biotechnology 18 (2), 159-163.

Chu, C.H., Bjeldanes, L.F., 1981. Effect of diamines, polyamines and tuna fish extracts on the binding of histamine to mucin in vitro. Journal of Food Science 47, 79-80

Cilliers, M.I., Van Wyk, C.J., 1985. Histamine and tyramine content in South African wines. South African Journal of Enology and Viticulture 6, 35-40.

Coton, E., Rollan, G.C., Lonvaud-Funel, A., 1998. Histidine carboxylase of Leuconostoc Oenos 9204: purification, kinetic properties, cloning and nucleotide sequence of the Hdc gene. Journal of Applied Microbiology 84, 143-151.

Csomos, E., Simonne, L., 2002. Comperative analysis regarding the free amino acid content of different wines. Élelmezési Ipar 56 (9), 264-268.

Del Prete, V., Costantini, A., Cecchini, F., Morassut, M., Garcia-Moruno, E., 2009. Occurrence of biogenic amines in wine: the role of grapes. Food Chemistry 112 (2), 474-481.
García-Villar, N., Hernández-Cassou, S., Saurina, J., 2007. Characterization of wines through the biogenic amine contents using chromatographic techniques and chemometric data analysis. Journal of Agricultural and Food Chemistry 55 (18), 7453-7461.

Gerbaux, V., Monamy, C., 2000. Biogenic amines in Burgundy wines. Contents and origin in wines. Revue Française dOenologie 183, 25-28.

Glaser, J.A., Foerst, D.L., McKee, G.D., Quave, S.A., Budde, W.L., 1981. Trace analysis for wastewater. Environmental Science and Technology 15, 1426-1430.

Glória, M.B.A., Watson, B.T., Simon-Sarkadi, L., Daeschel, M.A., 1998. A survey of biogenic amines in Oregon Pinot Noir and Cabernet Sauvignon wines. American Journal of Enology and Viticulture 49, 232-279.

Herbert, P., Cabrita, M.J., Ratola, N., Laureano, O., Alvés, A., 2004. Free aminoacids and biogenic amines in wine and musts from the Alentejo region. Evolution of amines during alcoholic fermentation and relationship with variety, sub-region and vintage. Journal of Food Engineering 66, 315-322.

Herbert, P., Santos, L., Alvés, A., 2001. Simultaneous quantification of primary and secondary amino acids and biogenic amines in musts and wines using OPA/3 MPA/FMOC-Cl fluorescent derivatives. Journal of Food Science 66, 13191325.

Iñiguez-Crespo, M., Vázquez-Lasa, B., 1994. Determination of biogenic amines and other amines in wine by an optimized HPLC method with polarity gradient elution. American Journal of Enology and Viticulture 45 (4), 460-463.

Izquierdo-Pulido, M.I., Vidal-Carou, M.C., Mariné-Font, A., 1993. Determination of biogenic amines in beers and their raw materials by ion-pair liquid chromatography with post-column derivatization. Journal of AOAC International 76, 1027-1032.

Jiménez-Moreno, N., Torrea, D.G., Ancín, C.A., 2003. Changes in amine concentrations during aging of red wine in oak barrels. Journal of Agricultural and Food Chemistry 57, 5732-5737.

Jung, H.Y.P., Bjeldanes, L.F., 1979. Effects of cadaverine on histamine transport and metabolism in isolated gut sections of the guinea pig. Food and Cosmetics Toxicology 17, 629-632.

Lavizzari, T., Veciana-Nogués, M.T., Bover-Cid, S., Mariné-Font, A., Vidal-Carou, M.C., 2006. Improved method for the determination of biogenic amines and polyamines in vegetable products by ion-pair high-performance liquid chromatography. Journal of Chromatography A 1129, 67-72.

Leitão, M.C., Marques, A.P., San-Romão, M.V., 2005. A survey of biogenic amines in commercial Portuguese wines. Food Control 16 (3), 199-204.

Lonvaud-Funel, A., 1999. Lactic acid bacteria in the quality improvement and depreciation of wine. Antonie van Leeuwenhoek 76, 317-331.

Lonvaud-Funel, A., 2001. Biogenic amines in wines: role of lactic acid bacteria. FEMS Microbiology Letters 199, 9-13.

Lonvaud-Funel, A., Joyeux, A., 1994. Histamine production by wine lactic acid bacteria: isolation of a histamine producing strain of Leuconostoc Oenos. Journal of Applied Bacteriology 77, 401-407.

Loukou, Z., Zotou, A., 2003. Determination of biogenic amines as dansyl derivatives in alcoholic beverages by high-performance liquid chromatography with fluorimetric detection and characterization of the dansylated amines by liquid chromatography-atmospheric pressure chemical ionisation mass spectrometry. Journal of Chromatography A 996, 103-113.

Mafra, I., Herbert, P., Santos, L., Barros, P., Alvés, A., 1999. Evaluation of biogenic amines in some Portuguese quality wines by HPLC fluorescence detection of OPA derivatives. American Journal of Enology and Viticulture 50, 128-132.

Martínez, A., Riu, J., Busto, O., 2000. Validation of bias in multianalyte determination methods. Application to RP-HPLC derivatizing methodologies. Analytica Chimica Acta 406 (2), 257-278.

Maynard, L.S., Schenker, V.J., 1962. Monoamine-oxidase inhibition by ethanol in vitro. Nature 196, 575-576.

Moreno-Arribas, M.V., Polo, M.C., Jorganes, F., Muñoz, R., 2003. Screening of biogenic amine production by lactic acid bacteria isolated from grape must and wine. International Journal of Food Microbiology 84, 117-123.

Ough, C.S., Crowell, E.A., Kunke, R.E., Vilas, M.R.S., Lagier, S., 1987. A study of histamine production by various wine bacteria in model solution and in wine. Journal of Food Processing and Preservation 12, 63-70.

Ough, C.S., Daudt, C.E., 1981. Quantitative determination of volatile amines in grapes and wines. I. Effect of fermentation and storage temperature on amine concentrations. American Journal of Enology and Viticulture 32 (3), 185-188.

Pogorzelski, E., 1992. Studies of the formation of histamine in must and wines from elderberry fruit. Journal of the Science of Food and Agriculture 60, 239-244.

Rivas-Gonzalo, J.C., Santos-Hernández, J.F., Mariné-Font, A., 1983. Study of the evolution of tyramine content during the vinification process. Journal of Food Science 48, 417-418.

Rollán, G.C., Farías, M.E., Manca de Nadra, M.C., 1995. Characterization of two extracellular proteases from Leuconostoc oenos. World Journal of Microbiology and Biotechnology 11, 153-155

Romero, R., Bagur, M.G., Sánchez-Viñas, M., 2000. Optimization of experimental variables in the dabsyl chloride derivatization of biogenic amines for their determination by RP-HPLC. Chromatographia 51 (7-8), 404-410.

Romero, R., Jönsson, J.Å., Gázquez, D., Bagur, M.G., Sánchez-Viñas, M., 2002. Multivariate optimization of supported liquid membrane extraction of biogenic amines from wine samples prior to liquid chromatography determination as dabsyl derivatives. Journal of Separation Science 25, 584-592.

Sandler, M., Reynolds, G.P., 1976. Does phenylethylamine cause schizophrenia? Lancet $1,70-71$.

Silla-Santos, M.H., 1996. Biogenic amines: their importance in food. International Journal Food Microbiology 29, 213-231. 
Soleas, G.J., Carey, M., Goldberg, D.M., 1999. Method development and cultivarrelated differences of nine biogenic amines in Ontario wines. Food Chemistry $64,49-58$.

Soufleros, E., Barrios, M.L., Bertrand, A., 1998. Correlation between the content of biogenic amines and other wine compounds. American Journal of Enology and Viticulture 49, 266-277.

Taylor, S.L., 1986. Histamine food poisoning: toxicology and clinical aspects. Critical Reviews in Toxicology 17, 91-128.

Taylor, S.L., Lieber, E.R., 1979. In vitro inhibition of rat intestinal histamine-metabolizing enzymes. Food and Cosmetics Toxicology 17, 237-240.

Torrea, D. Ancín, C., 2001. Influence of yeast strain on biogenic amines content in wines: relationship with the utilization of amino acids during fermentation. American Journal of Enology and Viticulture 52, 185-190.
Torrea, D., Ancín, C., 2002. Content of biogenic amines in a Chardonnay wine obtained through spontaneous and inoculated fermentations. Journal of Agricultural and Food Chemistry 50, 4895-4899.

Vidal-Carou, M.C., Ambattle-Espunyes, A., Ulla-Ulla, M.C., Mariné-Font, A., 1990. Histamine and tyramine in Spanish wines: their formation during winemaking. American Journal of Enology and Viticulture 41, 160-167.

Vidal-Carou, M.C., Lahoz-Portolés, F., Bover-Cid, S., Mariné-Font, A., 2003. Ion-pair high-performance liquid chromatographic determination of biogenic amines and polyamines in wine and other alcoholic beverages. Journal of Chromatography A 998, 235-241.

Zee, J.A., Simard, R.E., L'Heureux, L., Tremblay, J., 1983. Biogenic amines in wines. American Journal of Enology and Viticulture 34, 6-9. 